\title{
Research on Automatic Monitoring in Students' Abnormal Online Behavior Based on Data Mining
}

\author{
Shujie Liang \\ Guangdong Maoming Preschool Teachers College, Maoming, Guangdong 525000, China
}

Keywords: Data mining, Internet access, Abnormal behavior, Automatic monitoring

\begin{abstract}
With the rapid development of big data technology, the data processing ability of all walks of life has been greatly improved. All walks of life can dig out effective information from the data or analyze abnormal data, conduct detailed analysis and detection, effectively deal with some potential security problems, and ensure the safe operation of the industry. For the management of students' online behavior, big data technology can help managers collect students' online behavior data, extract valuable information from the data through a series of algorithms, and identify the students with abnormal behavior, so as to make managers pay more attention to such students. This paper will start from the behavior characteristics of students' online users, introduce the functions of analysis and monitoring system about network abnormal behavior, and put forward some big data technologies to effectively improve the quality of management.
\end{abstract}

\section{Introduction}

Students' online behavior is different from that of social personnel, and they spend more time on the internet, which causes a large number of non-structured behavior data. How to deal with these huge and different types of data and extract abnormal behaviors from them requires a variety of algorithms. Therefore, the research on automatic monitoring system of students' network abnormal behavior has become an important topic in the field of big data development.

\section{Behavior Characteristics of Online Students}

\subsection{Large Number of Users}

With the continuous improvement of the popularity of modern network and education, and the advancement of students' household living standards, at present, students' learning and life are inseparable from the network. Therefore, in recent years, the number of online students has increased dramatically. At the same time, the number of young netizens has increased proportionally and has generated a great deal of data.

\subsection{Complex and Changeable Online Behavior}

Online students are usually growing up and keep strong curiosity about many new things on the Internet. Therefore, their network behavior is also random, complex and changeable. In addition, mobile network equipment has an appeal to students, but they possess poor self-control and self-management ability, which makes their network behavior irregular, and is greatly affected by the changes of their growth and surrounding environment. Many schools do not have the time to guide students to surf the internet healthily, which leads to students being attracted by negative information when browsing the web, indulged in online games and live network, and may even result in economic disputes such as being cheated and online loans.

\subsection{Weak Safety Awareness}

Students usually lack the awareness of network security and self-protection because of their younger age and less experience. For example, after using the public network, they does not log out personal accounts in time and leave personal account password, which results in information 
disclosure. At the same time, due to strong curiosity, they usually get interested in some confusing information and links on the network, and may fall into some dangerous network traps. Moreover, due to the improper use of the network by individuals, hackers may invade the campus network, which threatens its confidentiality and then affects the public security of the campus network.

\section{Data Mining Technology}

\subsection{The Concept and Connotation of Data Mining Technology}

Data mining is a kind of information discovery technology for database, which is an important research technology in the field of computer database. Its main function is to provide a certain basis for decision-making. Based on machine learning, data acquisition and other technologies, it can analyze the collected data automatically, make the including ratiocination and conclude certain rules, which provides reference for the formulation of management rules, help managers to make scientific decisions and effective management, and reduce the risk of management to some degree. Data mining usually includes data cleaning, data conversion, data preprocessing and the implementation process of data mining.

\subsection{Data Mining Technology Involved in Students’ Online Behavior Monitoring}

Due to the randomness and variability of students' network behavior, a variety of data mining technologies are usually needed to provide support.

\subsubsection{Information Collection}

Due to the large number of online students and the huge amount of online data and information, collecting students' online behavior information needs to be applied to statistical knowledge, database technology and distributed technology.

\subsubsection{Data Cleaning}

The collected information is roughly cleaned, and the data of non students' online behavior is filtered out.

\subsubsection{Data Preprocessing}

After data cleaning, there may be noise data, abnormal data or missing data, which may affect the accuracy of the final analysis results. Therefore, it is also necessary to process and screen out high-quality and accurate data.

\subsubsection{Data Analysis and Mathematical Model}

After a series of processing, high-quality data is effectively analyzed through the appropriate algorithm, and finally a scientific mathematical model is established, which presents visual results of the network user behavior analysis for reference by managers.

\section{Automatic Monitoring Algorithm of Students' Abnormal Online Behavior Based on Data Mining}

Based on the principle of big data, we propose a set of systematic data algorithm for automatic monitoring of students' network abnormal behavior.

\subsection{Data Collection Algorithm of Students' Online Behavior}

In order to collect a large number of students' online behavior data, our behavior monitoring system needs to classify and summarize the structured and unstructured data of students. Among them, the structured data mainly includes network life data deployed on campus, such as punch in dormitory, class attendance, achievements of educational administration system and campus One-Card usage data. The unstructured data is mainly generated by students' free browsing through campus network. Gathering these data usually needs some scraping tools, such as stream 
data processing and crawler.

\subsection{Data Analysis Algorithm of Students’ Online Behavior}

Due to the randomness of students' online behavior, the data produced by them has the characteristics of discrete type. In the analysis, it is necessary to design association analysis, feature analysis, classification prediction, anomaly analysis and TopN analysis. Only by integrating these algorithms can we extract effective information from a large number of behavior data.

\subsection{Establish the Prediction Model of Students' Online Behavior}

After analyzing the data of students' online behavior, it is necessary to use matlab and spss for modeling according to the results. On the basis of statistics, big data is clustered to find out the relationship factor and main influence factor. By fitting and forecasting methods, the outlier behavior analysis model and emotional information mining model are established for students to grasp their life state and mental health. For the students with abnormal behavior, we need to analyze their action trajectory and social situation. Different factors have different influence on growth characteristics. We need to calculated by weight method and obtain the life portrait of students who stray from the group. In the concrete form of statistical images, graphs and charts, it provides early warning materials for managers, so as to plan ahead as a preventive measure and truly realize the management goal of "safe campus".

\subsection{Build a Visual Operation Platform for Automatic Monitoring of Students' Online Behavior}

The mainstream big data framework Hadoop is used to connect the big data system with the campus management system and form a visual platform for the analysis results of students' behavior data, so that managers can remotely monitor students' online behavior by using this system and grasp the effective information of behavior data. In addition, the automatic monitoring system can also classify students' online behaviors and transmit them to different management departments for analysis. For example, upload the data of campus One Card and online consumption to the student financial management system, the data of punching in dormitory and class attendance to the student logistics system, and the students' scores to the educational administration management system. Through each department performing its own duties, the huge data is divided into data with different functions, which improves the efficiency of data processing and reduces the repetitive work in data processing.

\section{Advantages and Disadvantages of Automatic Monitoring System for Students' Online Behavior}

The introduction of automatic monitoring system of students' online behavior is helpful to realize campus administrators' comprehensive mining and in-depth analysis of students' behavior data. It can control students' behavior in advance and predict the development of students with abnormal behavior. Before the potential problems occur, campus administrators can take measures to minimize the risks. Due to the adoption of remote monitoring and intelligent early warning, the system can also give students some freedom and basic life and entertainment will not be disturbed. The drawback is that the system also restricts students' freedom of surfing the internet to a certain extent, which reduces the security of network privacy and exists some limitation.

\section{Conclusion}

The detection technology of students' online behavior based on data mining mainly relies on the development of computer technology. Through computer algorithm analysis and simulation, we need to realize the data acquisition, data analysis and data prediction of students' online behavior. Through the deepening mining and analysis of various analysis modules, mathematical models and the students' online data, the results are processed by visualization, so that the student management 
department can understand the characteristics of students' online behavior according to the results, managers can carry out effective student management and early warning work, timely help students solve problems in learning and life, avoid falling into network trap or addicting network, and truly realize intelligent digital campus.

\section{Acknowledgment}

Project of science and Technology Department of Guangdong Province "Research and application of smart home security technology based on Internet of things and cloud computing" Project number: 2018S001411

\section{References}

[1] Wang Shaochun. Implementation of Online Behavior Management and Construction of a Safe and Green Campus Network. Journal of Liaoning Institute of Economic Management, No.04, pp.26-29, 2009.

[2] Xing Xuemei, Liu Jianfeng. Discussion on the Deployment of Online Behavior Management System in Campus Network. Network Security Technology and Application, No.07, pp.125-128, 2012.

[3] Zhao Xiaodong. Campus Network Security Analysis and Research Countermeasures. Industry and Technology Forum, No.06, pp.104-108, 2011.

[4] Guo Zili. Research on College Students' Education Management under the Background of the Internet. News Front, No.23, pp.89-91, 2018.

[5] Fan Xiao, Ni Ting. On the Innovation of Education and Management of College Student Party Members. Intelligence, No.34, pp.36-39, 2018. 